\title{
2 Transport and retention of Phytophthora capsici zoospores in saturated porous media
}

3 Sangho Jeon, ${ }^{\dagger}$ Charles S. Krasnow, ${ }^{\dagger}$ Caitlin K. Kirby, ${ }^{\ddagger}{ }^{\S}$ Leah L. Granke, ${ }^{\dagger, ~}{ }^{\|}$Mary K. Hausbeck, ${ }^{\dagger}$ and Wei Zhang ${ }^{\dagger,}$, *

$5{ }^{\dagger}$ Department of Plant, Soil and Microbial Sciences, Michigan State University, East Lansing, MI

$6 \quad 48824$

$7 \quad{ }^{\ddagger}$ Department of Geological Sciences, Michigan State University, East Lansing, MI 48824

8 § Environmental Science and Policy Program, Michigan State University, East Lansing, MI 48824

$9 \quad$ "Crop Protection Discovery, Dow AgroSciences, Indianapolis, IN 46268

10 *Corresponding author. Dr. Wei Zhang, Address: 1066 Bogue ST RM A516, East Lansing, MI

11 48824, United States; Tel: 517-353-0471; Fax: 517-355-0270; Email: weizhang@msu.edu.

\section{Content}

17 S1. Preparation and Characterization of P. capsici Zoospores and Porous Media

18 S2. XDLVO and $\alpha_{\text {theory }}$ and $k_{\mathrm{d}}$ theory Calculations

2115 pages, 9 figures, 2 tables, and 5 equations 


\section{S1. Preparation and Characterization of P. capsici Zoospores and Porous Media}

Preparation of Zoospore Suspension. To produce $P$. capsici zoospores, the culture was grown on V-8 agar (UCV8), which consisted of $840 \mathrm{~mL}$ distilled water, $160 \mathrm{~mL}$ unclarified V8

26 juice, $30 \mathrm{mM} \mathrm{CaCO}_{3}$, and $1.5 \%$ agar. The isolate was maintained on $\mathrm{UCV} 8$ at $25^{\circ} \mathrm{C}$ under

27 continuous fluorescent lighting. After 7-8 days, sterile distilled water was added to the culture, $P$.

28 capsici sporangia were scraped from the surface of the agar, and the resulting suspension was

29 placed into a 50- $\mathrm{mL}$ centrifuge tube. The tube was incubated at $4^{\circ} \mathrm{C}$ for $30-45$ minutes and then

30 at room temperature for 30 minutes to allow for zoospore release from sporangia. Since zoospores

31 are negatively geotropic, a stock zoospore suspension was obtained by taking the top portion of

32 the suspension, which excluded solid growth media, hyphal fragments, and sporangia. To

33 determine the concentration of the zoospore suspension, a 1-mL aliquot was placed into a 1.7-mL

34 microcentrifuge tube, vortexed for 70 seconds to induce zoospore encystment, and a $10-\mu \mathrm{L}$ aliquot

35 was pipetted onto a clean hemacytometer for counting (Bright-Line, Hausser Scientific, Horsham 36 PA).

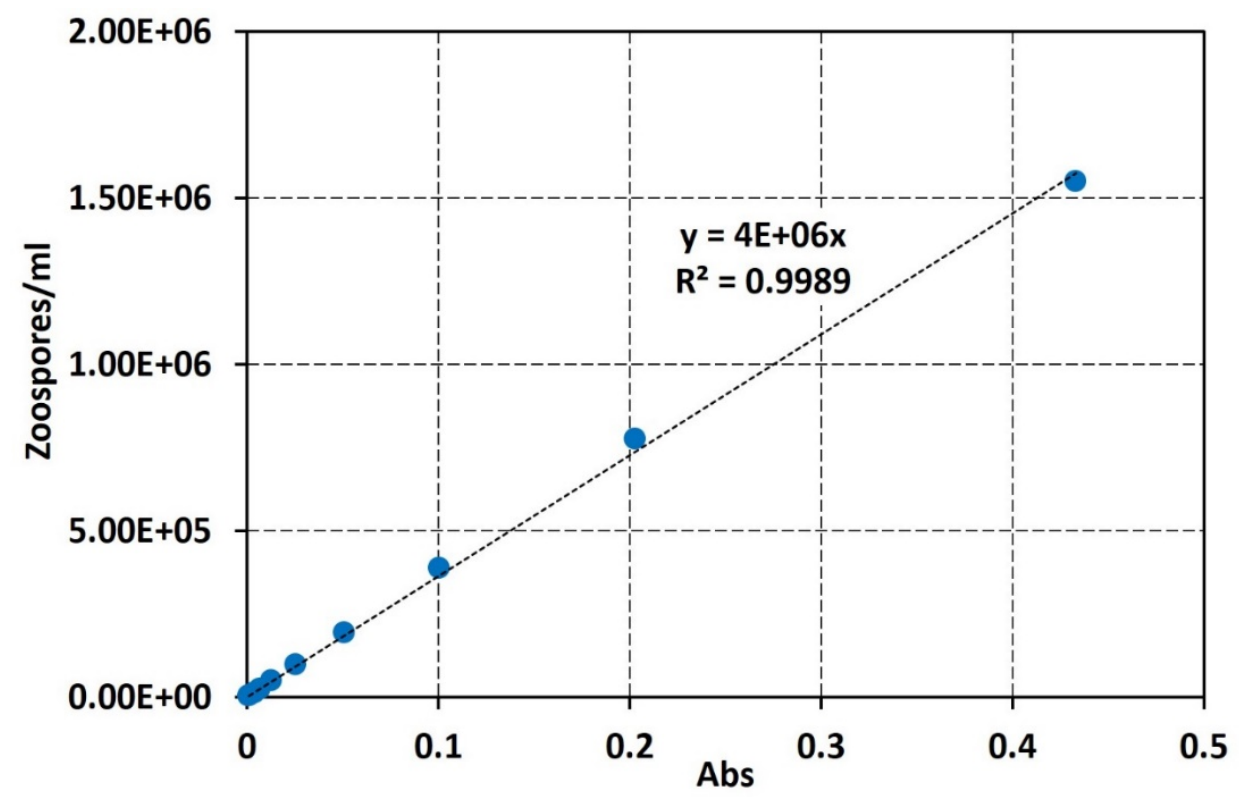

38 Figure S1. Observed $P$. capsici zoospore number concentrations in relation to absorbance. 
SEM Imaging of Zoospores. To observe the zoospores by scanning electron microscope

40 (SEM), ${ }^{1} 8$ drops of the zoospore suspension was mixed with an equal quantity of $4 \%$

41 glutaraldehyde buffered at $\mathrm{pH} 7.4$ with $0.1 \mathrm{M}$ sodium phosphate. Fixation was allowed to proceed

42 for 1 hour at $4^{\circ} \mathrm{C}$. A 12-mm round glass coverslip was coated with Poly-L-Lysine (Sigma Aldrich

43 P1399) by pressing a drop of 1\% Poly-L-Lysine solution downward on a plastic petri dish for 10

44 minutes and then gentle rinsing with several drops of water. One drop of the zoospores fixed in

45 suspension was placed on the wet Poly-L-Lysine coated coverslip surface and settled for 10

46 minutes. The coverslip was then gently rinsed with several drops of water, sequentially immersed

47 in 25\%, 40\%, 50\%, 60\%, 75\%, and 95\% ethanol solution for 10 minutes, and finally placed in $100 \%$

48 ethanol for 10 minutes for three times. The samples were dried in a critical point dryer (Balzers

49 Model 010, Balzers Union Ltd., Balzers, Liechtenstein) using liquid $\mathrm{CO}_{2}$ as the transitional fluid,

50 mounted on aluminum stubs with carbon suspension cement (SPI Supplies, West Chester, PA),

51 coated with osmium ( $\approx 15$ nm thickness) in a NEOC-AT osmium coater (Meiwafosis Co., Ltd.,

52 Osaka, Japan), and finally examined by a SEM with cold field emission electron emitter (JEOL

53 JSM-7500F, JEOL Ltd, Tokyo, Japan).

Iron Oxide Coating of Sand. To produce iron oxide (goethite, $\alpha$-FeOOH) coated sand,

55200 gram of clean sand was added to a mixture of 200-mL 0.05 M ferrous chloride solution and

56 40-mL $1 \mathrm{M} \mathrm{NaHCO}_{3}$ solution. The slurry was stirred for $1.5 \mathrm{hr}$ with magnetic bar to introduce

57 oxygen into the suspension and achieve uniform coating. During this process, Fe (II) in the slurry

58 was gradually oxidized to Fe (III), as shown by the color changes in Figure S2B. After 1.5 hours

59 of mixing, the coated sand was washed using copious amount of DI water, and then oven dried at

$60110{ }^{\circ} \mathrm{C}$ for 24 hours. Finally, a reddish-brown coating was formed (Figure S2C). This procedure

61 was repeated four times in total in order to increase Fe content of the coated sands. To create IOCS 
62 with a greater iron content, the mixture was stirred at a higher speed with a stirrer (RW11, IKA,

63 Germany) for a longer time. To determine iron content, IOCS was soaked in $2.0 \mathrm{M} \mathrm{HCl}$ for 48

64 hours at room temperature until coated iron was completely dissolved. Iron concentration in the

65 prepared solutions was measure by atomic absorption spectroscopy (AAnalyst 400, PerkinElmer,

66 Waltham, MA). To measure the $\zeta$-potentials of IOCS and uncoated sand surfaces, a 5-gram sand

67 sample was ultrasonicated in $15 \mathrm{~mL}$ deionized (DI) water for 30 minutes and then vortexed to re-

68 suspend sand particles prior to the 206-min settling. The top 5-cm suspension was taken for the $\zeta$ -

69 potential measurements. This suspension approximately contained sand colloids smaller than 2

$70 \mu \mathrm{m}$, assuming the Stokes’ law and particle density of $2.65 \mathrm{~g} / \mathrm{cm}^{3}$. Each $\zeta$-potential measurement

71 was repeated six times and the average value was calculated.

72



73 B.

74

75
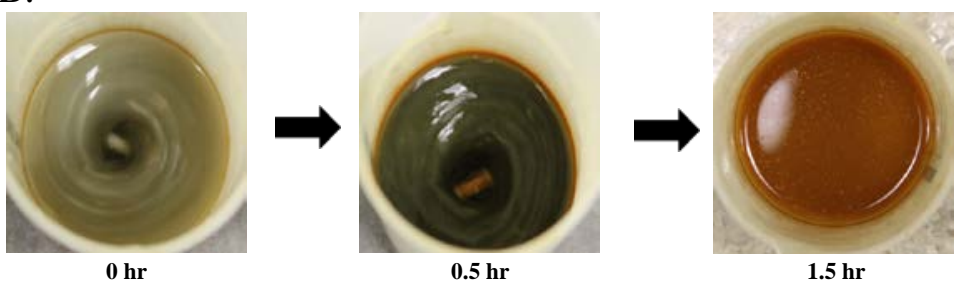

C.

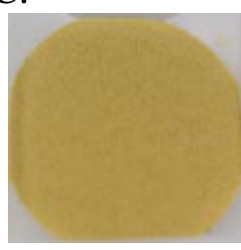

Repeat 1time

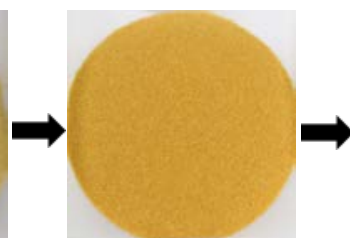

Repeat 2 times

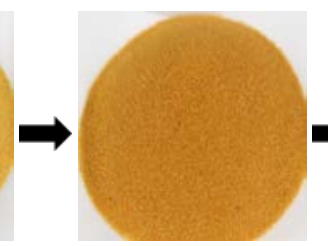

Repeat 3 times

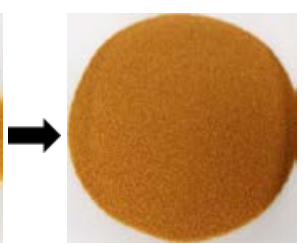

Repeat 4 times

Figure S2. Schematic of preparation procedure for iron oxide coated sand (IOCS) (A), and temporal visual changes of the preparation slurry (B) and IOCS (C). 


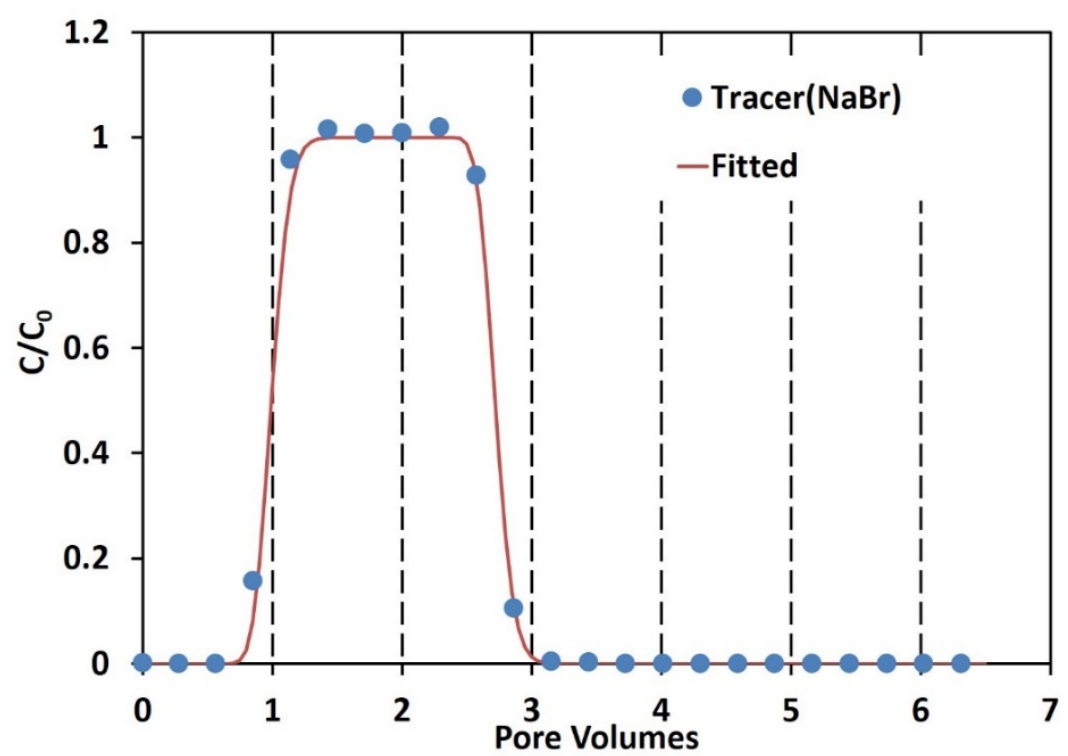

80 Figure S3. Observed and fitted breakthrough curves of bromide tracer through saturated column 81 packed with uncoated sand $(250-500 \mu \mathrm{m})$.
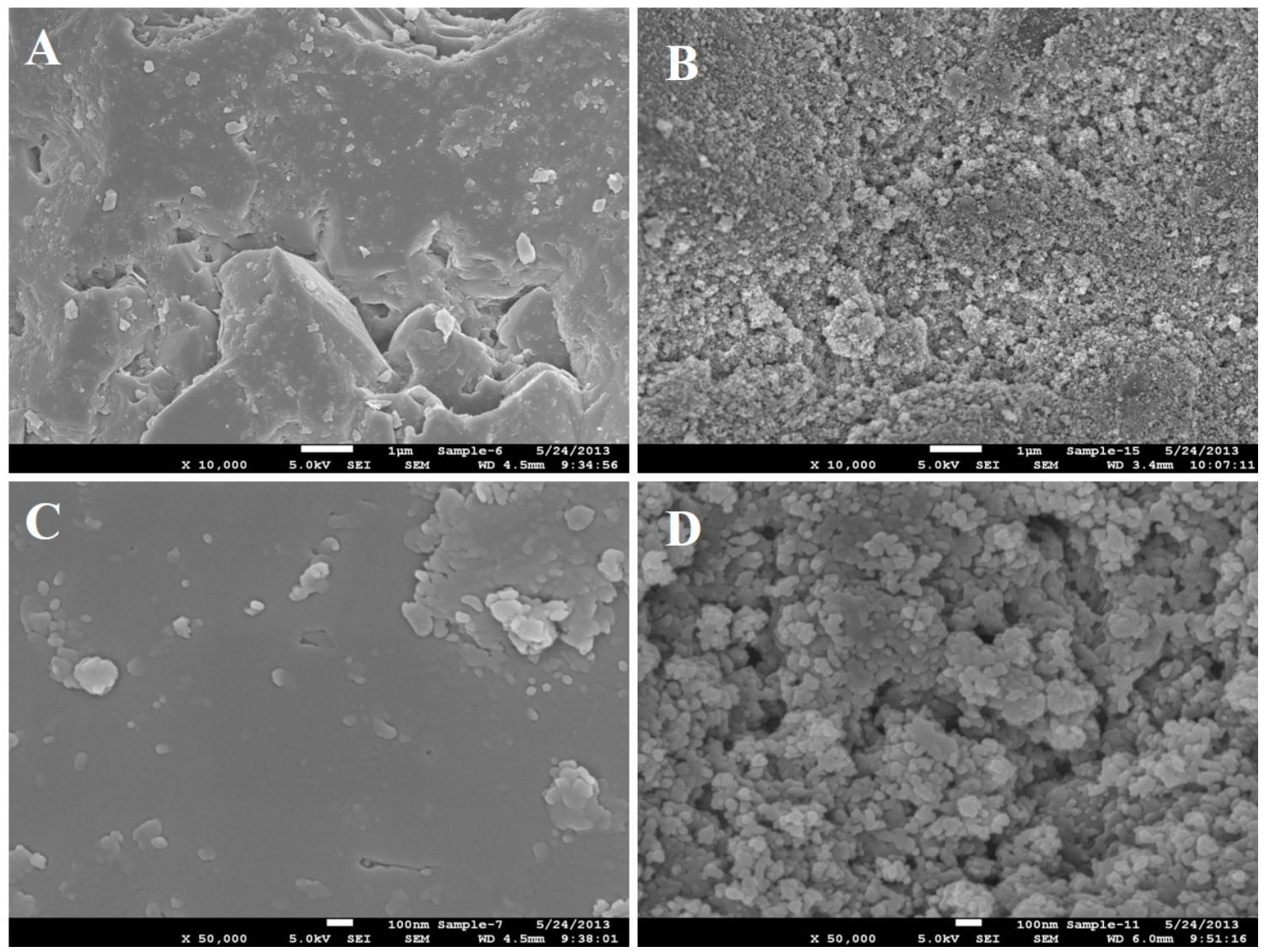

84 Figure S4. SEM images of Ottawa sand (A: $\times 10,000$ and C: $\times 50,000)$ and iron oxide coated sand

85 (B: $\times 10,000$ and D: $\times 50,000)$ of $250-500 \mu \mathrm{m}$. 

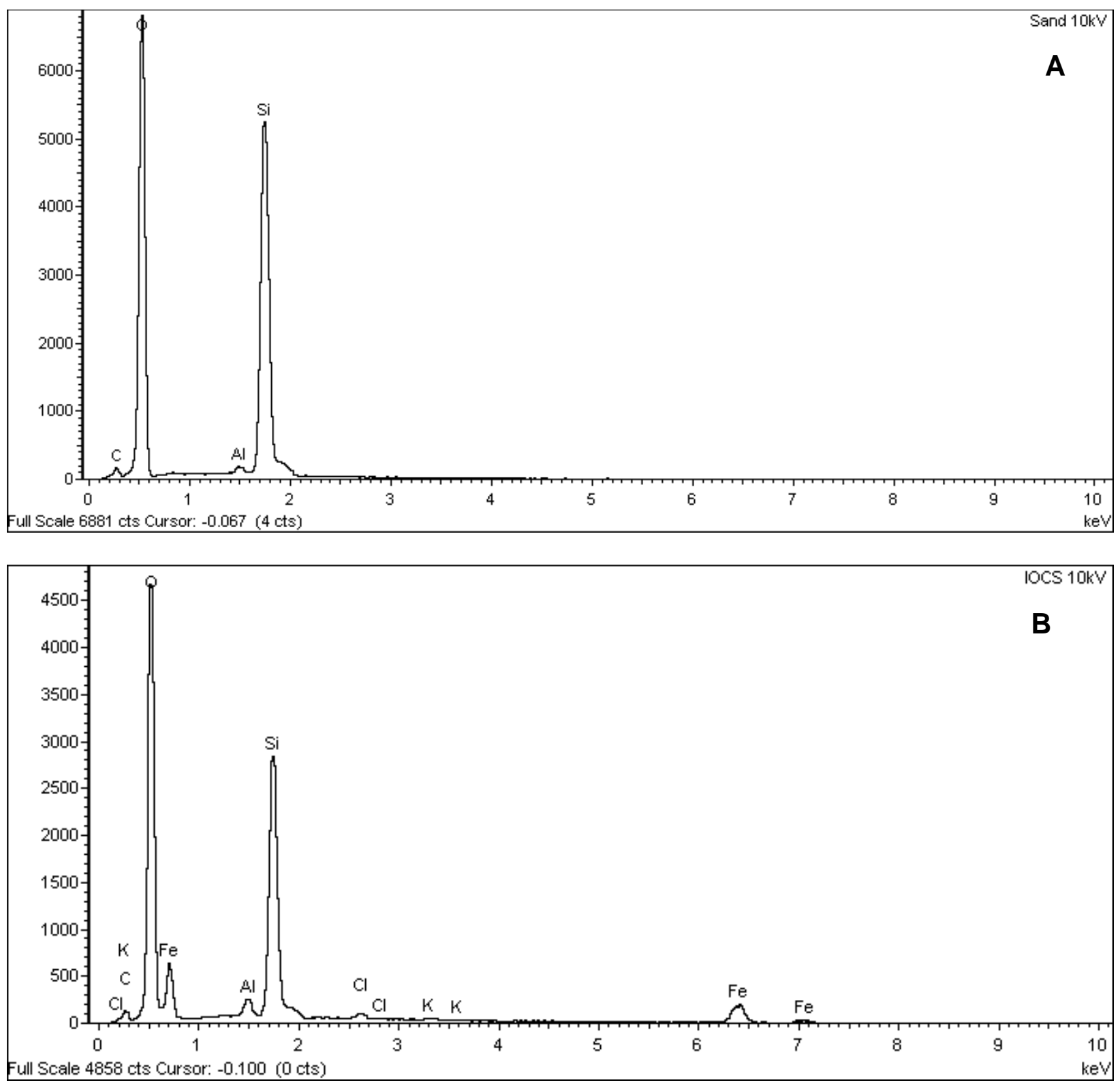

88 Figure S5. Energy-dispersive X-ray spectra of uncoated (A) and iron oxide coated sand (B). 89 
90 Table S1. Electrophoretic Mobility (EPM) and $\zeta$-potential of Uncoated and Iron Oxide Coated 91 Sand.

\begin{tabular}{|c|c|c|c|c|c|c|c|}
\hline \multirow[b]{2}{*}{ Solution chemistry } & \multirow[b]{2}{*}{$\mathrm{pH}$} & \multicolumn{2}{|c|}{ Uncoated sand } & \multicolumn{2}{|c|}{$0.13 \%$ Fe IOCS } & \multicolumn{2}{|c|}{$0.22 \%$ Fe IOCS } \\
\hline & & $\begin{array}{c}\text { EPM } \\
\left(\mu \mathrm{m} \mathrm{cm} \mathrm{s}^{-1}\right. \\
\left.\mathrm{V}^{-1}\right)\end{array}$ & $\begin{array}{l}\zeta \text {-potential } \\
(\mathrm{mV})\end{array}$ & $\begin{array}{c}\text { EPM } \\
(\mu \mathrm{m} \mathrm{cm} \\
\left.\mathrm{s}^{-1} \mathrm{~V}^{-1}\right)\end{array}$ & $\begin{array}{c}\zeta- \\
\text { potential } \\
(\mathrm{mV})\end{array}$ & $\begin{array}{c}\text { EPM } \\
(\mu \mathrm{m} \mathrm{cm} \\
\left.\mathrm{s}^{-1} \mathrm{~V}^{-1}\right)\end{array}$ & $\begin{array}{c}\zeta- \\
\text { potential } \\
(\mathrm{mV})\end{array}$ \\
\hline $0.4 \mathrm{mM} \mathrm{NaHCO}_{3}$ & 7.7 & $-3.43 \pm$ & -43.8 & -1.41 & -18.0 & -0.62 & -7.9 \\
\hline + $9.6 \mathrm{mM} \mathrm{NaCl}$ & \pm 0.5 & 0.16 & \pm 2.1 & \pm 0.09 & \pm 1.2 & \pm 0.04 & \pm 0.6 \\
\hline $0.4 \mathrm{mM} \mathrm{NaHCO}_{3}$ & & $-0.95 \pm$ & -12.1 & 0.28 & 3.6 & 0.58 & 7.3 \\
\hline + $3.2 \mathrm{mM} \mathrm{CaCl}_{2}$ & & 0.04 & \pm 0.5 & \pm 0.03 & \pm 0.4 & \pm 8.35 & \pm 0.1 \\
\hline $0.4 \mathrm{mM} \mathrm{CH}_{3} \mathrm{COONa}$ & $4.0 \pm$ & $-1.86 \pm$ & -23.8 & 1.35 & 17.2 & 2.96 & 37.8 \\
\hline $\begin{array}{l}+2.6 \mathrm{mM} \mathrm{CH}_{3} \mathrm{COOH} \\
+9.6 \mathrm{mM} \mathrm{NaCl}\end{array}$ & 0.3 & 0.09 & \pm 1.2 & \pm 0.04 & \pm 0.5 & \pm 0.08 & \pm 1.0 \\
\hline $0.4 \mathrm{mM} \mathrm{CH} \mathrm{CH}_{3} \mathrm{COONa}$ & & $-0.70 \pm$ & -8.9 & 1.79 & 22.8 & 3.40 & 43.4 \\
\hline $\begin{array}{l}+2.6 \mathrm{mM} \mathrm{CH}_{3} \mathrm{COOH} \\
+3.2 \mathrm{mM} \mathrm{CaCl}_{2}\end{array}$ & & 0.04 & \pm 0.5 & \pm 0.04 & \pm 0.6 & \pm 0.15 & \pm 1.9 \\
\hline
\end{tabular}

92 


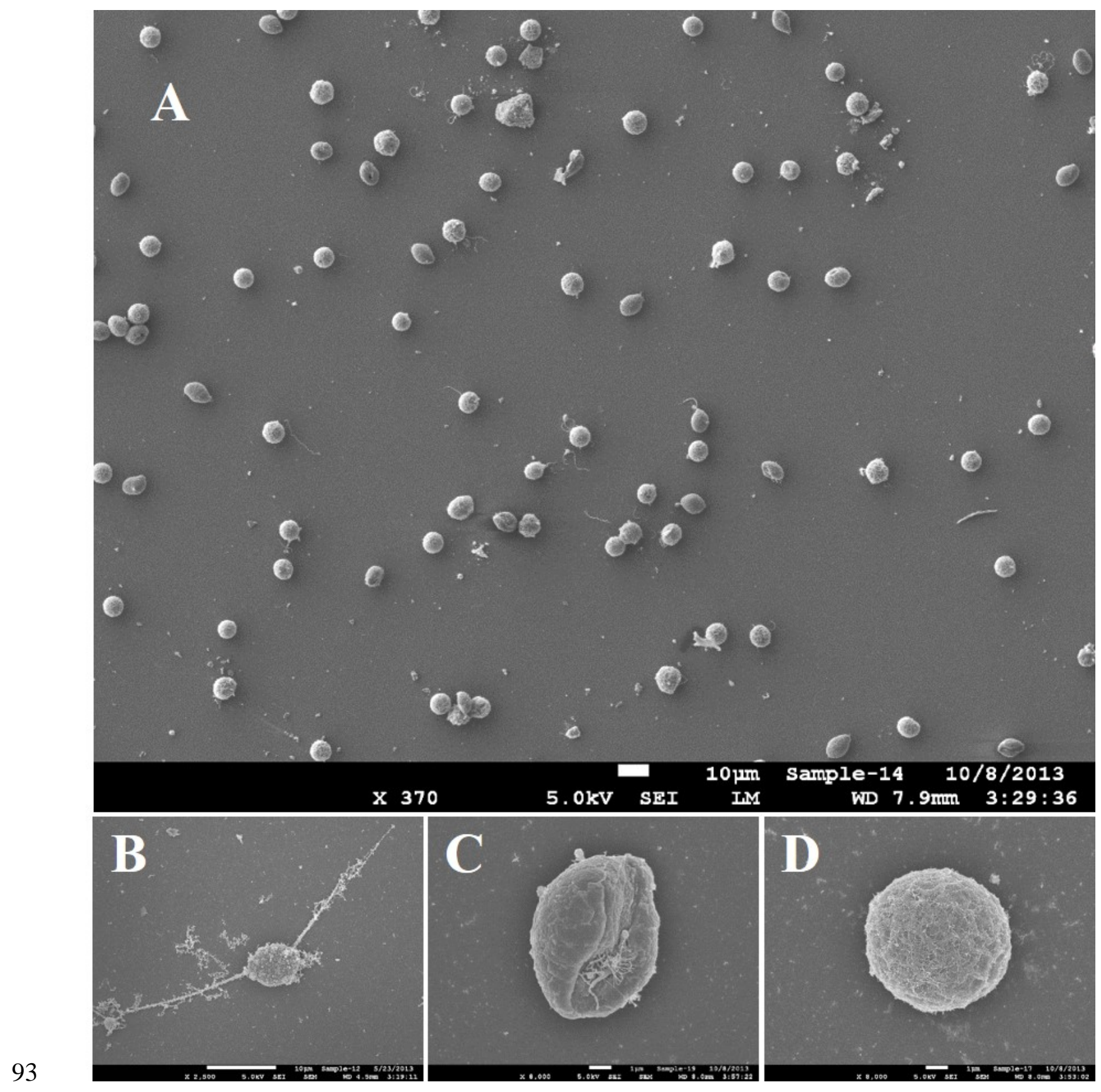

94 Figure S6. SEM images of encysted (A, C and D) and biflagellate $P$. capsici zoospores (B) in 95 deionized water.

96 

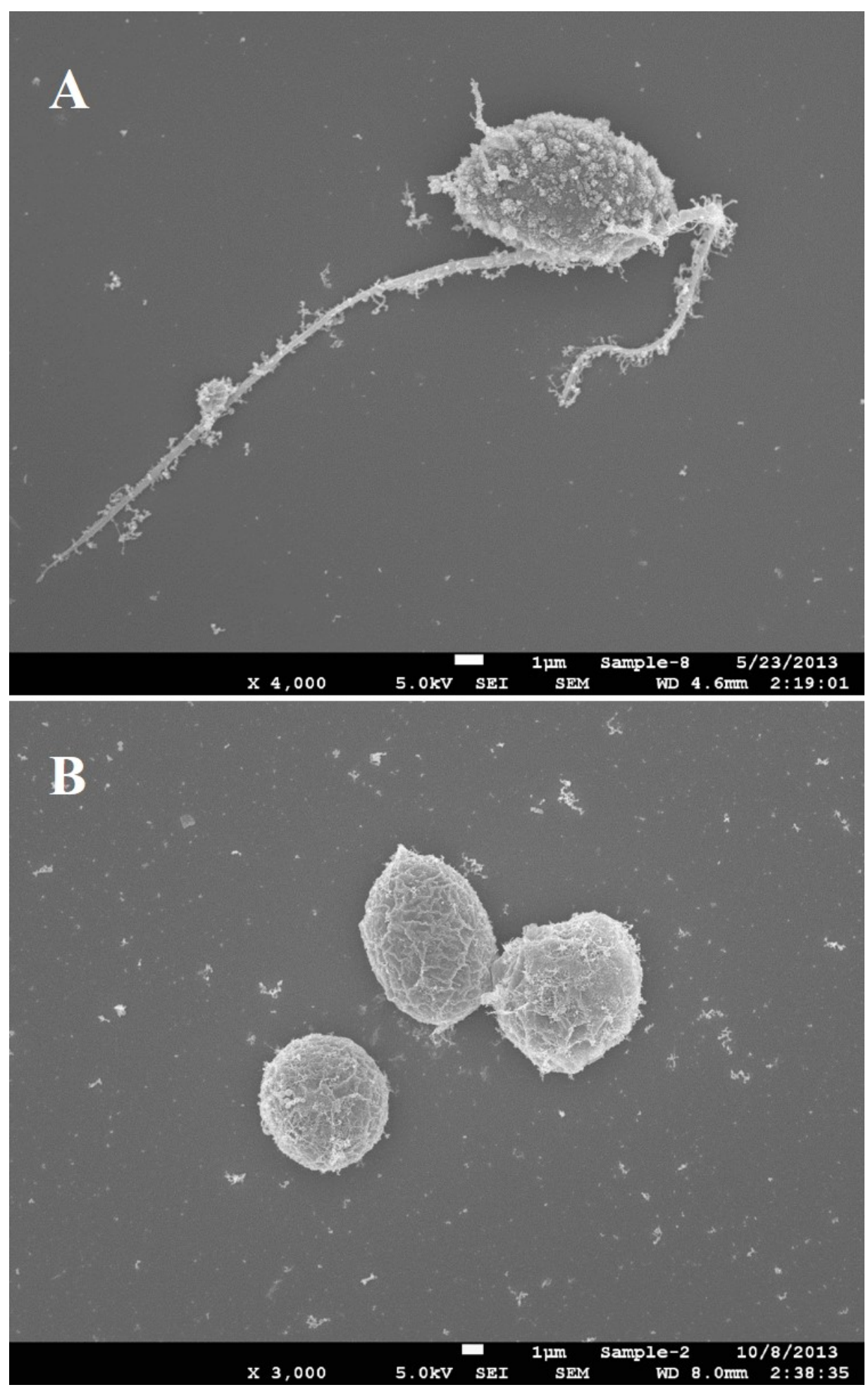

98 Figure S7. SEM images of biflagellate (A) and encysted (B) P. capsici zoospores in $\mathrm{NaCl}$ solution 99 at $\mathrm{pH} 7.2$ and ionic strength $10 \mathrm{mM}$.

100 


\section{S2. XDLVO and $\boldsymbol{\alpha}_{\text {theory }}$ and $\boldsymbol{k}_{\mathrm{d}}$ theory Calculations}

The extended Derjaguin-Landau-Verwey-Overbeek (XDLVO) interaction energies,

103 including Lifshitz-van der Waals $\left(\Phi^{\mathrm{LW}}\right)$, electrical double layer $\left(\Phi^{\mathrm{EL}}\right)$, and Born repulsion $\left(\Phi^{\mathrm{BR}}\right)$

104 interactions, were calculated for a zoospore interacting with the solid-water interface (SWI), i.e.,

105 uncoated sand or IOCS surface. The total XDLVO interaction energy ( $\Phi^{\mathrm{XDLVO}}$ ) was determined

106 as a function of separation distance $(x)$ :

$107 \Phi^{\mathrm{XDLVO}}(x)=\Phi^{\mathrm{LW}}(x)+\Phi^{\mathrm{EL}}(x)+\Phi^{\mathrm{BR}}(x)$

108 The $\Phi^{\mathrm{LW}}, \Phi^{\mathrm{EL}}$, and $\Phi^{\mathrm{BR}}$ were calculated via:

109

$\Phi^{\mathrm{LW}}(x)=-\frac{A_{132} a_{\mathrm{p}}}{6 x}\left(1+14 x / \lambda_{\mathrm{c}}\right)^{-1}$

110

$\Phi^{\mathrm{EL}}(x)=\pi \varepsilon \varepsilon_{0} a_{\mathrm{p}}\left\{2 \psi_{1} \psi_{2} \ln \left[\frac{1+\exp (-\kappa x)}{1-\exp (-\kappa x)}\right]+\left(\psi_{1}^{2}+\psi_{2}^{2}\right) \ln [1-\exp (-2 \kappa x)]\right\}$

$111 \Phi^{\mathrm{BR}}(x)=\frac{A_{132} \sigma^{6}}{7560}\left[\frac{8 a_{\mathrm{p}}+x}{\left(2 a_{\mathrm{p}}+x\right)^{7}}+\frac{6 a_{\mathrm{p}}-x}{x^{7}}\right]$

112 where $A_{132}$ is the Hamaker constant of the zoospore interacting with the SWI, $a_{\mathrm{p}}$ is the zoospore

113 radius (i.e., $3.5 \mu \mathrm{m}$ ), $\lambda_{\mathrm{c}}$ is the van der Waals interaction characteristic wavelength (i.e., about 100

$114 \mathrm{~nm}), \varepsilon$ is the dielectric constant of the medium (i.e., 80.1 for water at $293.15 \mathrm{~K}$ ), $\varepsilon_{0}$ is the vacuum

115 permittivity $\left(8.854 \times 10^{-12} \mathrm{C}^{2} \mathrm{~N}^{-1} \mathrm{~m}^{-2}\right), \psi_{1}$ and $\psi_{2}$ are the respective surface potential of the

116 zoospore and the SWI, $\kappa$ is the reciprocal electric double layer thickness (the Debye length $\left[\kappa^{-1}\right]$ ),

117 and $\sigma(0.5 \mathrm{~nm})$ is the collision diameter. The $\mathrm{A}_{132}$ value for the zoospore is unknown, therefore,

118 the $A_{132}$ of $6.5 \times 10^{-21} \mathrm{~J}$ was taken from the literature values widely used for bacteria and

119 Cryptosporidium oocysts. ${ }^{6-8}$ We used the $\zeta$-potentials in place of the surface potential. ${ }^{9}$ The

120 XDLVO calculations were performed for the encysted zoospores. The $\zeta$-potentials of the encysted 
121 zoospores in Table 1 under identical solution chemistry were averaged over several experimental

122 sets, as shown in Table S2. The $\zeta$-potentials of the uncoated sand and IOCS of 0.13\% Fe content

123 as listed in Table S2 were used to illustrate the XDLVO energy of the zoospore interacting with

124 the sand and IOCS surfaces. The calculated XDLVO energies were normalized with $k T$ where $k$ is

125 Boltzman constant $\left(1.381 \times 10^{-23} \mathrm{~J} \mathrm{~K}^{-1}\right)$ and $T$ is temperature in Kelvin. The XDLVO primary

126 energy maximum $\left(\Phi_{\max }\right)$ and second energy minimum $\left(\Phi_{2 \min }\right)$ are listed in Table S2 and the energy

127 profiles are shown in Figure S8. Theoretical attachment efficiency $(\alpha)$ is calculated from a Maxwell

128 model that includes colloid deposition in primary and secondary energy minimum. ${ }^{10-12}$

$\alpha=\alpha_{\mathrm{pri}}+\alpha_{\mathrm{sec}}=\int_{\sqrt{\Delta \Phi}}^{\infty} \frac{4}{\pi^{1 / 2}} E^{2} \exp \left(-E^{2}\right) d E+\int_{0}^{\sqrt{\Delta \Phi_{2 \min }}} \frac{4}{\pi^{1 / 2}} E^{2} \exp \left(-E^{2}\right) d E$

$129=1-\int_{\sqrt{\Phi_{2 \min }}}^{\sqrt{\Delta \Phi}} \frac{4}{\pi^{1 / 2}} E^{2} \exp \left(-E^{2}\right) d E$

$=1-\left(\operatorname{erf}(\sqrt{\Delta \Phi})-\sqrt{\frac{4 \Delta \Phi}{\pi}} \exp (-\Delta \Phi)\right)+\left(\operatorname{erf}\left(\sqrt{\Phi_{2 \text { min }}}\right)-\sqrt{\frac{4 \Phi_{2 \min }}{\pi}} \exp \left(-\Phi_{2 \text { min }}\right)\right)$

130 where $E^{2}$ is the particle kinetic energy normalized by $k T$, and $\Delta \Phi$ is the sum of $\Phi_{\max }$ and $\Phi_{2 \min }$.

131 The calculated $\alpha$ values are provided in Table S2 below.

132 Table S2. XDLVO Calculations and Attachment Efficiency for an Encysted Zoospore Interacting 133 with the Solid-Water Interface (SWI). ${ }^{a}$

\begin{tabular}{|c|c|c|c|c|c|c|c|}
\hline \multirow{2}{*}{ Zoospore-SWI } & \multirow{2}{*}{$\mathrm{pH}$} & \multirow{2}{*}{$\begin{array}{l}\text { Cation } \\
\text { type }\end{array}$} & \multicolumn{2}{|c|}{$\zeta$-potential (mV) } & \multirow{2}{*}{$\begin{array}{l}\Phi_{\max } \\
(k T)\end{array}$} & \multirow{2}{*}{$\begin{array}{l}\Phi_{2 \min } \\
(k T)\end{array}$} & \multirow{2}{*}{$\alpha$} \\
\hline & & & Zoospore & SWI & & & \\
\hline Zoospore-Sand & High $\mathrm{pH}$ & $\mathrm{Na}^{+}$ & -18.0 & -43.8 & 1770 & 6.6 & 0.996 \\
\hline Zoospore-Sand & $(7.7 \pm 0.5)$ & $\mathrm{Ca}^{+}$ & -12.1 & -12.1 & 137 & 12.0 & 1.000 \\
\hline Zoospore-IOCS & & $\mathrm{Na}^{+}$ & -18.0 & -18.0 & 675 & 8.7 & 0.999 \\
\hline Zoospore-IOCS & & $\mathrm{Ca}^{+}$ & -12.1 & 3.6 & $f a v^{b}$ & fav & 1.000 \\
\hline Zoospore-Sand & Low $\mathrm{pH}$ & $\mathrm{Na}^{+}$ & -9.9 & -23.8 & 301 & 9.8 & 1.000 \\
\hline Zoospore-Sand & $(4.0 \pm 0.3)$ & $\mathrm{Ca}^{+}$ & -7.8 & -8.9 & fav & fav & 1.000 \\
\hline Zoospore-IOCS & & $\mathrm{Na}^{+}$ & -9.9 & -17.2 & fav & fav & 1.000 \\
\hline Zoospore-IOCS & & $\mathrm{Ca}^{+}$ & -7.8 & -22.8 & fav & fav & 1.000 \\
\hline
\end{tabular}

$134{ }^{a} \Phi_{\max }=$ primary energy maximum, $\Phi_{2 \min }=$ second energy minimum, $\alpha_{\text {theory }}=$ theoretical 135 attachment efficiency; ${ }^{b}$ fav indicate the favorable condition with the absence of $\Phi_{\max }$.

136 As shown in Table S2 and Figure S8, at pH $7.7 \pm 0.5$ the zoospore-sand interaction was

137 characterized by high $\Phi_{\max }$ and appreciable $\Phi_{2 \min }$, whereas the zoospore-IOCS interaction had 
138 lower $\Phi_{\max }$ and deeper $\Phi_{2 \min }$ in the presence of $\mathrm{Na}^{+}$, and no $\Phi_{\max }$ in the presence of $\mathrm{Ca}^{2+}$. At $\mathrm{pH}$

$1394.0 \pm 0.3$, only the zoospore-sand interaction had $\Phi_{\max }$ and $\Phi_{2 \min }$ in the presence of $\mathrm{Na}^{+}$, whereas

140 all other interactions had no $\Phi_{\max }$. Because of either the sizable $\Phi_{2 \min }$ or the absence of $\Phi_{\max }$, the

141 calculated $\alpha$ was essentially 1, suggesting complete retention of the zoospores by the porous media.

142 Additionally, theoretical deposition rate coefficient $\left(k_{\mathrm{d}}\right.$ theory $)$ can be estimated as: ${ }^{13}$

$143 \quad k_{\mathrm{d} \text { theory }}=\frac{3}{2} \frac{(1-f)}{d_{\mathrm{c}}} v \alpha \eta_{0}$

144 where $d_{\mathrm{c}}$ is the effective collector diameter, $f$ is the porosity (0.35), $v$ is the pore water velocity

$145\left(0.77 \mathrm{~cm} \mathrm{~min}^{-1}\right)$, and $\eta_{0}$ is the single-collector contact efficiency calculated by the Tufenkji and 146 Elimelech equation. ${ }^{13}$ The effective collector diameter was $375 \mu \mathrm{m}$ for the $250-500 \mu \mathrm{m}$ fraction 147 and $652 \mu \mathrm{m}$ for the 500-804 $\mu \mathrm{m}$ fraction, respectively. The zoospore density was $1.075 \mathrm{~g} \mathrm{~cm}^{-3}$ 148 similar to Cryptosporidium parvum oocysts. ${ }^{8}$ The calculated $\eta_{0}$ was $0.0275-0.0333$, and the $k_{\mathrm{d}}$ theory 149 was estimated to be $0.316-0.667$. Combining with Eq. (2), the theoretical effluent mass recovery 150 (MER) was calculated to be 0-0.006, again suggesting almost complete retention. 

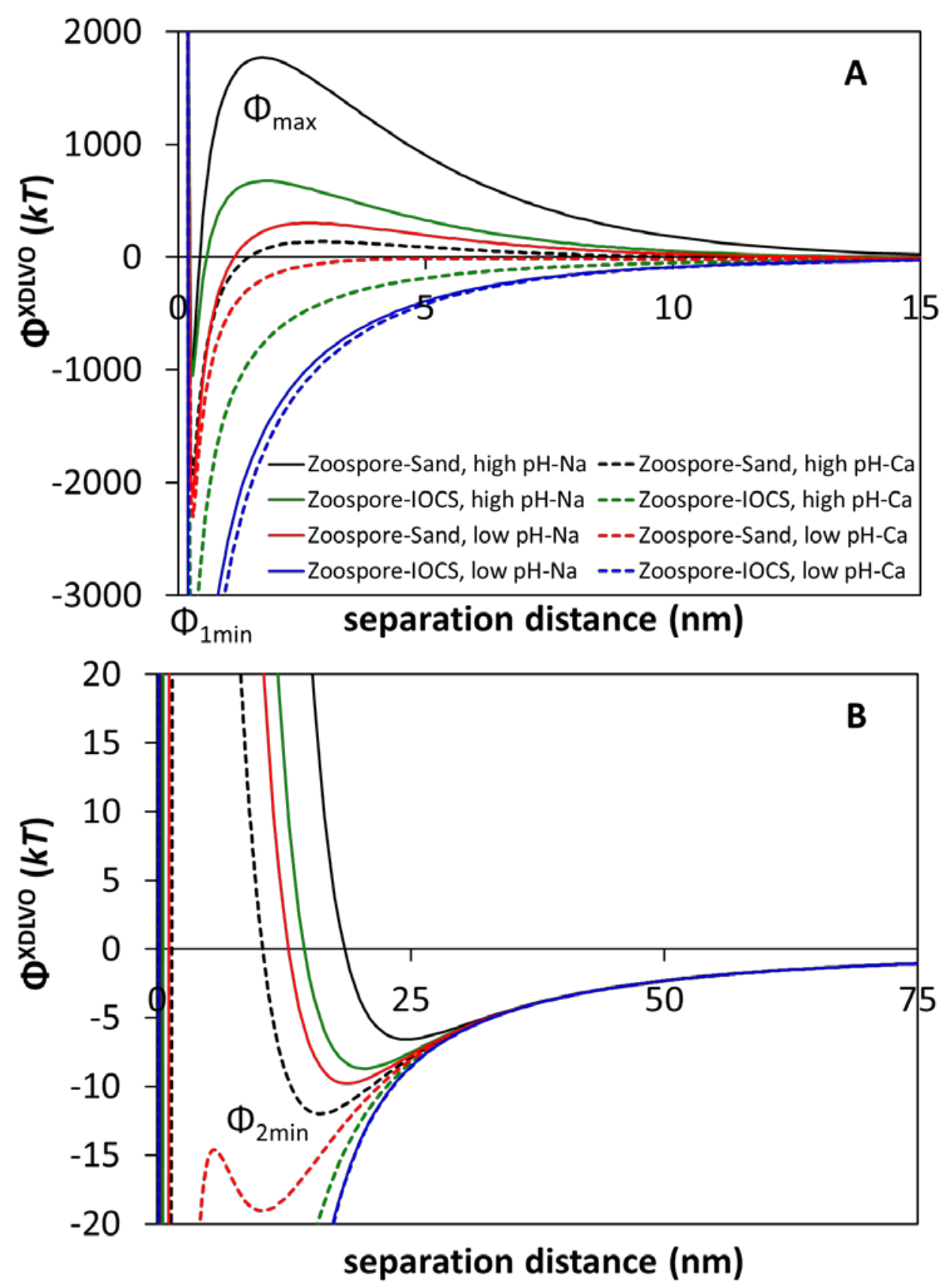

Figure S8. Total XDLVO interaction energies of zoospore interacting with uncoated sand surface or iron oxide coated sand (IOCS) surface: (a) primary energy minimum $\left(\Phi_{1 \min }\right)$ and maximum $\left(\Phi_{\max }\right)$ and (b) secondary energy minimum $\left(\Phi_{2 \min }\right)$. 


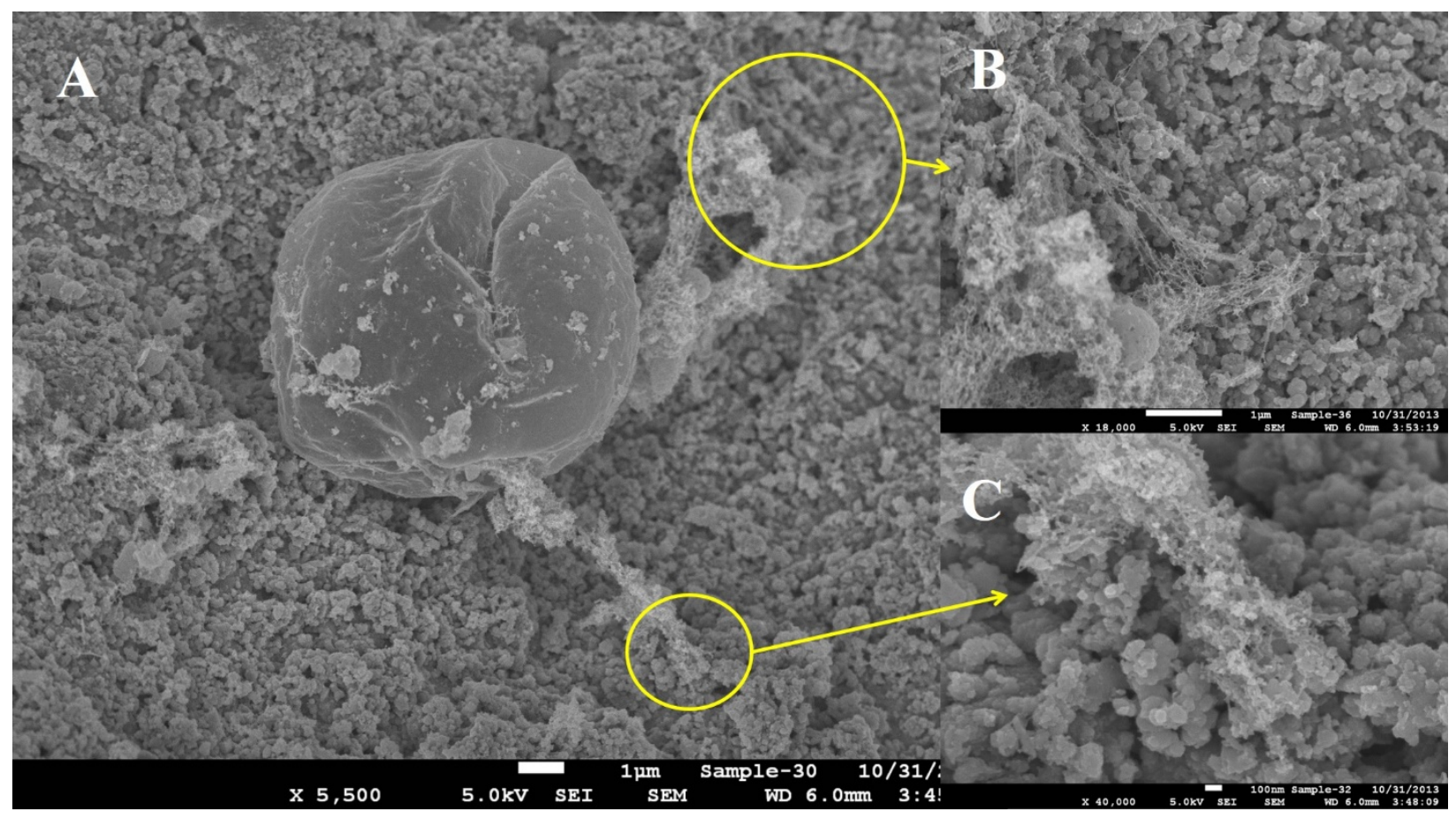

159 Figure S9. SEM images of encysted $P$. capsici zoospores attached on iron oxide coated surface in 160 the presence of $\mathrm{Na}^{+}$.

161 


\section{References Cited in Supporting Information}

163 (1) Flegler, S. L.; Heckman Jr, J. W.; Klomparens, K. L., Scanning and transmission electron microscopy: an introduction. Oxford University Press: Oxford, UK, 1993.

165 (2) Gregory, J., Approximate expressions for retarded van der waals interaction. J. Colloid 166 Interface Sci. 1981, 83, (1), 138-145.

167 (3) Hoek, E. M. V.; Agarwal, G. K., Extended DLVO interactions between spherical particles 168 and rough surfaces. J. Colloid Interface Sci. 2006, 298, (1), 50-58.

169 (4) Hogg, R.; Healy, T. W.; Fuerstenau, D. W., Mutual coagulation of colloidal dispersions. 170 Transactions of the Faraday Society 1966, 62, 1638-1651.

171 (5) Ruckenstein, E.; Prieve, D. C., Adsorption and desorption of particles and their 172 chromatographic separation. AICHE J. 1976, 22, (2), 276-283.

173 (6) Redman, J. A.; Walker, S. L.; Elimelech, M., Bacterial adhesion and transport in porous 174 media: Role of the secondary energy minimum. Environ. Sci. Technol. 2004, 38, (6), 1777-1785.

175 (7) Kuznar, Z. A.; Elimelech, M., Adhesion kinetics of viable Cryptosporidium parvum 176 oocysts to quartz surfaces. Environ. Sci. Technol. 2004, 38, (24), 6839-6845.

177 (8) Abudalo, R. A.; Bogatsu, Y. G.; Ryan, J. N.; Harvey, R. W.; Metge, D. W.; Elimelech, M., 178 Effect of ferric oxyhydroxide grain coatings on the transport of bacteriophage PRD1 and 179 Cryptosporidium parvum oocysts in saturated porous media. Environ. Sci. Technol. 2005, 39, (17), $180 \quad 6412-6419$.

181 (9) van Oss, C. J., Interfacial forces in aqueous media. 2nd ed.; CRC Taylor \& Francis: Boca 182 Raton, FL, 2006.

183 (10) Hahn, M. W.; O'Melia, C. R., Deposition and reentrainment of Brownian particles in 184 porous media under unfavorable chemical conditions: Some concepts and applications. Environ. Sci. Technol. 2004, 38, (1), 210-220.

(11) Shen, C.; Li, B.; Huang, Y.; Jin, Y., Kinetics of coupled primary- and secondary-minimum deposition of colloids under unfavorable chemical conditions. Environ. Sci. Technol. 2007, 41, (20), 6976-6982.

(12) Bradford, S. A.; Torkzaban, S., Determining Parameters and Mechanisms of Colloid Retention and Release in Porous Media. Langmuir 2015, 31, (44), 12096-12105.

(13) Tufenkji, N.; Elimelech, M., Correlation equation for predicting single-collector efficiency in physicochemical filtration in saturated porous media. Environ. Sci. Technol. 2004, 38, (2), 529536. 